\title{
O corpo como acesso ao divino na arte iluminada de William Blake
}

ANDRIO J. R. DOS SANTOS I

\section{Introdução}

$\mathrm{N}$

AS OBRAS do poeta, pintor e gravurista inglês William Blake (1757-1827) confluem diversas tradições místicas, artísticas, científicas e religiosas, cidas pelo esforço do artista em reinterpretá-las. O pano de fundo familiar possibilitou a Blake um contato com formas alternativas de tradição religiosa. Blake também era versado na tradição poética, particularmente naquelas de expressão protestante, como Milton. Seu interesse em Swedenborg e Boehme propiciou uma aproximação com correntes de misticismo judaico-cristão, ao passo que suas leituras de Locke, Newton e Bacon ofereceram-lhe familiaridade com a filosofia vigente e as ideias empiristas correntes. Além disso, sua posição ora ou outra ambígua em relação ao círculo de artístas em torno do livreiro Joseph Johnson alocava-o em uma espécie de lugar limítrofe da socidade politizada do período; um lugar que o permitia permanecer inteirado de discussões sobre estética, experiência, cultura, sensibildiade perceptiva, reforma política e inovações científicas, como as desenvolvidas por autores como Joseph Priestley, Mary Wollstonecraft, Thomas Paine e Erasmus Darwin. Tais obras e autores convergem vez que outra, em maior ou menor grau, nas obras blakeanas.

Não presumo que essa confluência se realize de forma homogênea, pois de maneira alguma todas essas linhas de pensamento poderiam ser conciliadas em uma obra, por mais extensa e intricanda que fosse. Considerando que Blake estava em contato com a produção efervescente da décade de 1790 inglesa - um momento permeando por aspirações revolicionárias e por um forte senso de mudança -, não parece inacurado mencionar que o autor não teria passado incólume às discussões apresentadas pelos referentes autores, particularmente sobre a forma de produção do conhecimento baseada na matriz empirista de tradição lockeana. A razão era a modea de ouro do século XVIII Inglês, um trunfo sobre o qual se concebia que a sociedade devia ser fundamentada. Pelo exercício da razão, as paixões, os instintos e o corpo, compreendidos geralmente como baixos, impuros e transitórios, deveriam ser domesticados em nome de um projeto útil.

Blake responde a isso em sua arte; na obra do autor, a experiência do corpo revela-se como uma das fontes de construção do conhecimento, o que, 
como muitas dicotomias exploradas pelo artista, apresenta-se alternadamente como espiritual e material. De fato, o pensamento de Blake sobre o corpo opera como uma espécie de princípio fundamental que permeia seus esforços imaginativos em relação à sua herança intelectual e à construção de sua visão de mundo. A noção de "visão" é fundamental para a compreensão da obra de Blake, isto porque, para o artista, a própria arte, que representa o caráter redentório do homem, está calcada no ato visionário. No entanto, em Blake, o caráter visionário não se apresenta como sinônimo de místico, embora autores como Paley (1985) e Connolly (2002) pareçam supor que sim. Frye (1990, p.87) traça essa distinção ao mencionar que o místico busca uma comunhão espiritual com o divino, ao passo que o visionário "cria ou reside em um mundo espiritual mais elevado, no qual os objetos de percepção foram transfigurados e estão carregados por uma nova intensidade de simbolismo". 1

Blake frequentemente associa "visão" à "inspiração", e ambos os termos à arte e ao divino, noções que tentam dar conta daquilo que o artista compreendia como o ato de ver além do mundo material, embora não de forma transcendente. A noção de visão blakeana compreende o movimento de ver o mundo espiritual a partir do material, espiritualizando-o, através do olho da imaginação. Ou seja, o acesso ao divino - o retorno ao Éden - está ligado ao caráter corporal do homem. Essa representação corporal, ao mesmo tempo calcada em tradições epstemológicas e ontológicas, é o que Tristanne Connolly (2002, p. 40) chama de "mystical empiricism" (empirismo místico). Matthew Green (2005) desenvolve uma noção semelhante, a qual propõe chamar de "visionary materlialism" (materialismo visionário), que aproxima noções um tanto antes apartadas em Blake, como filosofia natural e experiência profética. A partir de uma revisão crítica sobre questões persistentes na arte iluminada de William Blake, este artigo perpassa as concepções do artista a respeito do corpo e seu papel no acesso humano ao divino. Longe de tentar conformar correntes duais e conflituosas, o artigo tem o intuito de dar conta, na obra de Blake, da convergência politizada de diversas tradições distintas, ao mesmo tempo que me mantenho sensível às contradições geradas por esse processo de aproximação.

\section{Um corpo místico \& material: as paixões,}

\section{torções \& a exuberância da carne na arte de William Blake}

A primeira questão a ser examinada se refere à instância composicional e estilística da técnica de Blake. Tristanne Connolly (2002) utiliza-se da gravura Elohim Creating Adam (1795) (Figura 1) para discutir as concepções de Blake sobre o corpo humano, comentando que a obra representa uma afirmativa visual acerca da criação do corpo, assim como a respeito das idiossincrasias gráficas de Blake. De fato, o estilo de Blake, sublime, tende a maximizar e a magnificar imagens até o ponto em que pareçam distorcidas e anatomicamente incorretas. A gravura mencionada por Connolly (2002) exemplifica de forma satisfatória tais questões, uma vez que a autora lê uma imposição de força no ato de Elohim 


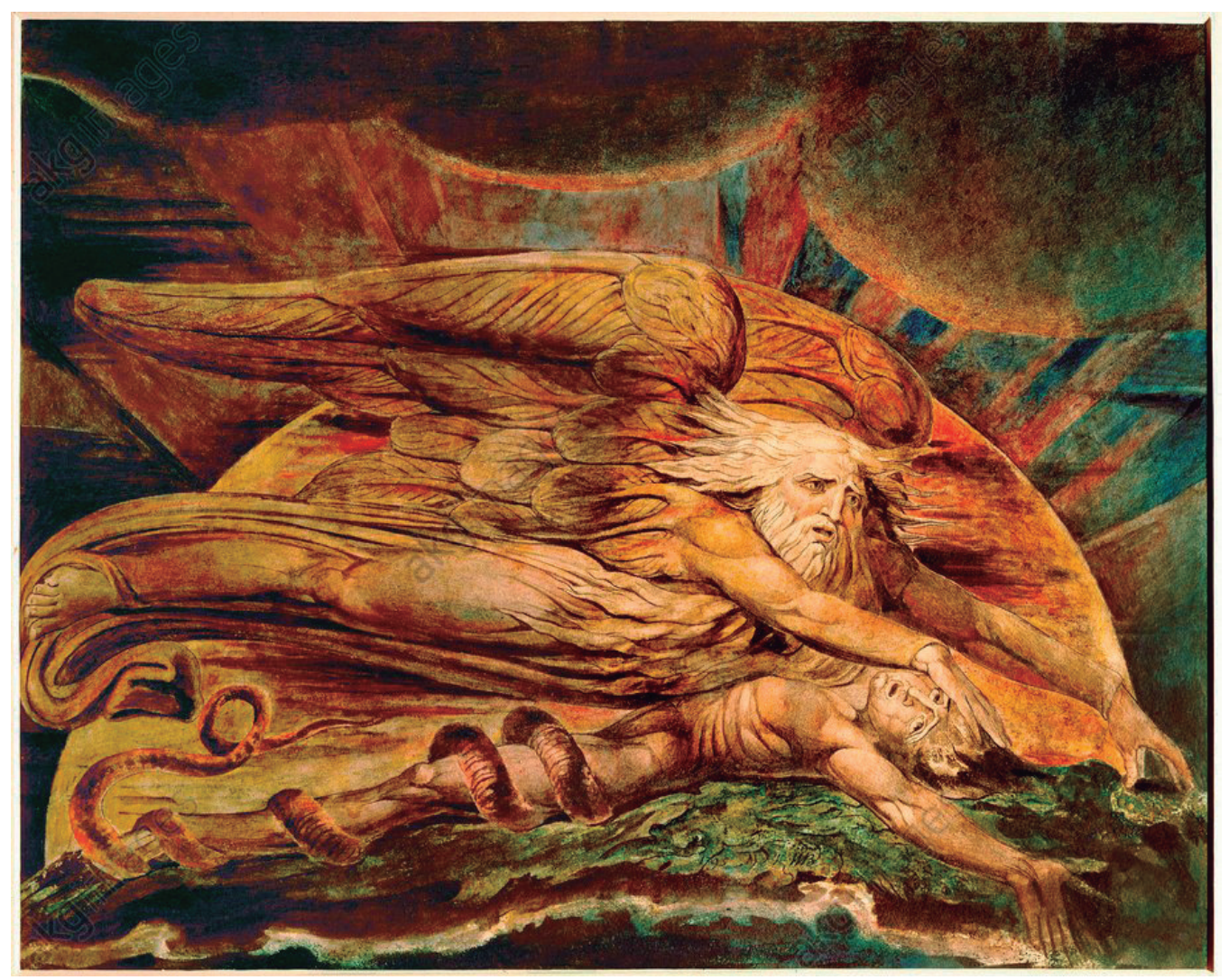

Fonte: Tate Galleries.

Figura 1 - Elohim Creating Adam, 1795.

pressionar a cabeça de Adam, ressaltando a aparente simetria entre os corpos. No entanto, o que mais salta aos olhos é o fato de, na figura de Elohim, praticamente inexistir um torso, ao mesmo tempo em que, ao fundo, veem-se representações de um sol, raios de sol e nuvens, imagens criadas com uma aparente preocupação geométrica, fato que contrasta com o aparente erro anatômico em Elohim.

A gravura, assim como boa parte dos corpos ilustrados por Blake, apresenta dificuldades ao mesmo tempo em que convida à interpretação. Ao ler essa imagem, Christopher Heppner (1995) aponta questões como o torso inexistente e a inviabilidade das asas da figura sustentarem-na no ar - questão que não parece tão digna de nota se consideramos que os elementos estilísticos da obra são mais pertinentes do que uma possível "análise aerodinâmica" de Elohim. A imagem se mostra de fato desconcertante, violenta, expressiva e dubiamente estranha. As asas, ainda que não sejam "aerodinâmicas", possuem um padrão exuberante, assim como a própria representação dos músculos, sugerindo algo de trágico e cósmico.

Ane K. Mellor (1974) comenta que a maioria das ilustrações produzidas por Blake apresenta figuras humanas como objetos centrais, representadas com 
linhas fortes, o que sugere que suas pinturas e livros iluminados seriam organizados em torno da forma humana. Connolly $(2002$, p.26) menciona que "pode parecer errôneo retratar as vicissitudes da carne de forma tão extrema. Ainda assim, ao imbuir corpos fraturados com elegância e detalhamento composicional, Blake retrata também o sofrimento que advém, inescapavelmente, da vida mortal", o que representaria "a conexão do corpo mortal com o ideal da Divina Forma Humana" (ibidem, p.27). Blake considera de fato que o homem foi privado da eternidade, seu estado natural, a partir da criação do corpo humano, algo possível de ser traçado em The Marriage of Heaven and Hell (1790), Europe: A Prophecy (1794a), Jerusalem e The [First] Book of Urizen (1794b).

Em Europe, a criação do corpo é descrita como um "dilúvio": “[...] the five senses whelm'd / In deluge o'er the earth-born man/ [...] And overwhelmed all except this finite wall of flesh" (Blake, 1794a, p.9). Associada à ideia de dilúvio, a passagem sugere algo de primitivo; a "inundação material" está diretamente ligada à mudança na natureza dos próprios sentidos, que, no pensamento místico-religioso de Blake, não eram contidos antes dessa mesma "inundação material". As mudanças sofridas pelos sentidos durante a criação do corpo compreendem solidificação, paralisia e encapsulamento, que sucedem aquilo que parece excessivamente flexível, instável e até doloroso movimento. Os órgãos dos sentidos estão em contato com o "heavens of heavens" (ibidem), ainda que flutuem em um espaço vasto e sem limites. Apesar de os órgãos serem descritos separadamente, eles mudam em sincronia, uma vez que a própria mudança sugere uma ligação entre esses mesmos órgãos dos sentidos. Por outro lado, o desdobramento da criação do corpo sugere segregação e, assim, os sentidos são apartados do infinito.

Em The Marriage, Blake apresenta uma noção de unidade em relação à existência espiritual e corporal humanas, defendendo que "Man has no Body distinct from his/Soul. For that called Body is a por-/tion of Soul discerned by the five senses" (Blake, 2011, p.94). Para Blake, o homem não possui corpo e alma distintas, sendo em vez disso uma criatura una, compósita, cujas distinções se fazem no âmbito da percepção corporal e espiritual. Se considerarmos que o corpo seria apenas uma porção da alma distinguida pelos cinco sentidos, a "inundação material" em Europe apresenta-se como uma espécie de solidificação de parte da alma humana, e não como a forja do corpo no intuito de conter ou de servir como recipiente à alma. Essa afirmativa contraria o dogma cristão, tanto católico quanto protestante, que lê o corpo como um invólucro passageiro - quando não impuro - para a alma imortal.

Blake considera que o corpo seja a única via de acesso à alma, compreensão que o autor articula na concepção de "sensual enjoyment" (apreciação sensual); tal noção diz respeito à ideia de que o homem tem a capacidade de reacessar o paraíso a partir do (re)conhecimento corporal, como se, através da exploração dos músculos, dos sentidos físicos e mesmo do ato sexual, o homem fosse capaz de retraçar o caminho da queda, empreendendo um tipo de retorno ao paraíso. 
Esse retorno seria imaginativo porque, para Blake, a imaginação está atrelada ao divino. $\mathrm{O}$ ato de imaginar, de criar arte, representa a capacidade profética do homem, um ato capaz de oferecer revelação (Frye, 1990). A noção de "apreciação sensual" é apresentada também em The Marriage e permeia a obra de Blake como um todo: "[...] the whole creation will be consumed and appear infinite and holy, whereas/ it now appears finite and corrupt./ This will come to pass by an improvement of sensual enjoyment" (Blake, 2011, p.104).

Heppner (1995) destaca a dubiedade da representação corporal em Elohim Creating Adam, ao passo que Connolly (2002) lê a exacerbação dos músculos como expressão de dor. Tais leituras se devem a certas características das representações corporais de Blake, que frequentemente se distendem além dos limites convencionais humanos, algo que pode, de fato, ser lido como uma imagem de angústia ou dor, ainda que eu não considere que este seja o caso. No entanto, vale mencionar a categorização sugerida por Janet Warner (1984, p. 87), que, ao comentar diversas figuras humanas nos livros iluminados de Blake, menciona as diferentes "Figures of Despair" (Figuras de Desespero) e "Figures of Energy" (Figuras de Energia) (ibidem). Mas a própria autora reconhece a dubiedade dessa caracterização, notando que as personagens de Blake, assim como suas representações, são frequentemente arquétipos ambíguos, uma noção que permanece no cerne de diversos comentários críticos relativos às representações de corpos em Blake.

Pode ser esclarecedor, nesse caso, traçar alguns comentários sobre Michelangelo, um dos pintores elogiados por Blake em seu Descriptive Catalogue (1809). A arte de Michelangelo é associada a ideias de contorção e paixão por pintores como o inglês Joshua Reynolds e o italiano Giorgio Vasari (Connolly, 2002), além de ser associada à noção de "magnificação" de corpos (Gombrich, 2012). De acordo com Heppner (1995), Vasari foi de grande importância para a formação de uma opinião geral sobre Michelangelo na Inglaterra do século XVIII, ainda que seus textos não estivessem disponíveis em inglês até a década de 1850. Heppner também menciona que a obra Painting Illustrated in three dialogues, containing some Choice Observations upon the Art, Together with the Lives of the most Eminent Painters, de William Aglionby, publicado pela primeira vez em 1685, apresenta o trabalho de Vasari, assim como um comentário do pintor acerca do Juizo Final de Michelangelo. No entanto, parece Heppner confunde - ao menos em suas referências - a obra de Aglionby com a de Vasari, Lives of the Most Eminent Painters, Sculptors and Architects. Este último apresenta de fato o comentário de Vasari (1912-1914, p.22) sobre Michelangelo:

[...] ele escolheu o mais árduo Objetivo sobre o qual se obter êxito, que consiste em demonstrar as verdadeiras proporções do mais difícil dos Objetos, que é o Corpo Humano $\mathrm{Nu}$; e também naquela que é a mais intricada das Habilidades, concernente às mais fortes afetações e paixões, compreendendo a maior variedade imaginável em todo o Mundo. Em tudo isso ele demonstrou ser o maior mestre de todo o Mundo. 
Vasari insiste que Michelangelo sintetiza aquilo que Aglionby afirma ser "a tarefa mais difícil da Arte, referente à contorção dos Membros e às Torções dos Músculos e à Contração de Nervos" (Aglionby, 1685, p.23). Tais características tornariam a obra de Michelangelo distintiva e particular e, por essa mesma razão, Reynolds (1959, p.176) afirma tratar-se de uma obra perigosa: "que Michelangelo era um tanto excêntrico em suas criações, não pode ser negado, e isso pode exigir circunspecção no estudo de suas obras; imitá-las é sempre perigoso e provar-se-á, por vezes, ridículo, por mais acurado que o trabalho possa parecer". Reynolds menciona que se certas características da obra de Michelangelo podem ser consideradas como falhas ou erros (anatomia, proporção etc.), eles assumem-se como marcas de uma mente independente e altamente criativa.

Em Discourses on Art, de 1723, Reynolds traça diversos argumentos no intuito de validar a grandeza da arte de Michelangelo, pois as características reconhecidas por Reynolds na arte de Michelangelo entram em confronto com suas noções de paixão e beleza. Para Reynolds, a beleza deve ser representada em seu estado perfeito, estático e intocável. Ou seja, a fim de expressar a beleza perfeita, o artista não deve representar paixões que distorçam e deformam as faces e corpos belos daqueles que pinta. No entanto, Michelangelo realiza justamente a operação contrária. Blake contraria e até ironiza Reynolds acerca dessa questão. Em suas Annotations to the work of Sir Joshua Reynolds, o artista escreve: "Que Absurdo. Paixão \& Expressão são a Beleza em $\mathrm{Si}$ - O Rosto que é Inapto à Paixão \& Expressão é Deformidade em Si” (Blake, 1988, p.653). Blake também menciona que a noção de Reynolds é algo que "seria apenas admirada por tolos" (ibidem). A ressalva de Reynolds e a admiração de Blake por Michelangelo estão fundamentadas da mesma questão. Além disso, Blake vai além, não apenas imitando, mas exagerando aquilo que Reynolds considera extremo e inimitável em Michelangelo: a contorção dos músculos e a expressão das paixões.

John Harvey (1977) comenta que as figuras de Blake tendem a ser excessivamente musculares, questionando o que ele chama de uma dúbia obsessão pelo sistema muscular, uma vez que o autor considera que os músculos são o que mais se destaca nas figuras humanas blakeanas, ao mesmo tempo em que boa parte delas não é anatomicamente correta. Seguindo a linha de raciocínio de Harvey (1977), eu poderia questionar por que Blake não intenta reproduzir a acuidade com que Michelangelo representava o corpo, uma vez que o artista britânico exaltava o italiano por sua técnica. Harvey (1977) sugere que Blake está mais interessado em representar o sistema muscular e a disposição dos corpos enquanto padrões, uma vez que esses padrões sugeririam movimento, tensão e paixão - questões caras à Blake - ainda que os corpos se apresentem anatomicamente incorretos. Heppner (1995, p.54) concorda com Harvey (1977), comentando que a ideia de reproduzir corpos enquanto padrões visa gerar "um tipo de hipérbole emocional". Tanto para Harvey quanto para Heppner, Blake valoriza expressão mais do que exatidão, uma das características que faz com que sua arte seja lida como sublime. 
Michelangelo, assim como Blake, retrata figuras humanas em situações não habituais a representações comuns de corpos e, como Heppner (1995, p.35) menciona, ambos os artistas aventuram-se "pelos vastos espaços de uma concepção concreta de reinos apocalípticos", uma noção visionária que condiz com os ideais artísticos de Blake. Connolly $(2002$, p.52) traça um paralelo entre as representações de corpos blakeanos e a técnica criada pelo artista no intuito de produzir seus livros iluminados, mencionando que "gravação em relevo assemelha-se, desse modo, mais do que em oco, ao ato de esfolar um indivíduo anatômico para revelar os sistemas que jazem abaixo da pele". Os corpos representados por Blake expressariam um tipo distinto de graça: "não se trata da graça do corpo mortal, mas de um corpo ideal percebido através da imaginação" (Connolly, 2002, p.61)

Trata-se de uma observação que materializa os comentários de Blake em The Marriage, obra em que o artista descreve simbolicamente seu processo de criação através da apresentação das diversas câmaras de uma "Casa de Impressão do Inferno". O mesmo pode ser dito em relação à afirmativa de que sua técnica seria capaz de oferecer revelação: "printing in the infernal method by/ corrosives, which in Hell are salutary and me-/dicinal, melting apparent surfaces away, and/ displaying the infinite which was hid" (Blake, 2011, p.104). Assim, nervos, músculos e órgãos dos sentidos possuiriam uma capacidade dual: ao mesmo tempo em que limitam a percepção humana, sua exploração oferece a capacidade de revelação. Ou seja, trata-se do sentido profético do corpo. Por sua vez, esta instância espiritualizada do corpo só pode ser percebida através da visão e da imaginação; a partir de uma operação de leitura que espiritualiza as imagens do mundo material e reconhece nelas as ressonâncias do divino.

Existe, na fortuna crítica de Blake, certo debate sobre o quanto das ideias do artista a respeito da espiritualização do corpo poderia ter sido fundamentado pela leitura de Disquisitions Relating to Matter and Spirit, de Joseph Priestley (1777), uma vez que Blake e Priestley compartilham ideias semelhantes em âmbito teológico, filosófico e político, além de frequentarem os mesmos espaços no círculo de artistas em torno do livreiro Joseph Johnson. John Mee (1992, p.138) menciona que "Priestley bem pode ter sido uma fonte direta" para a placa 4 de The Marriage e "uma importante, ainda que difusa, influência" (ibidem). Isso porque Priestley une noções espitituais e físicas, resgatando o cristianismo de sua usual trancendentalidade, o que pode sido atraente para Blake enquanto pensamento metafísico. Assim como Blake, Priestley considera a filosofia natural e a teologia como coisas intrisecamente conectadas, afirmando que o cristianismo só pode ser compreendido de forma correta a partir de uma perspectiva materialista: "com o auxílio do sistema materialista, o cristão remove o próprio alicerce de diversas doutrinas que degradaram e corromperam excessivamente o cristianismo" (Priestley, 1777, p.49).

Priestley trabalha a partir de uma concepção que mescla o espiritual aos princípios mecânicos em voga na ciência no século XVIII e, em vez de conceber 
um Deus que se afasta da natureza, o autor compreende Deus como uma força que se infunde em toda a existência. Essa representação de Deus baseia-se na noção de que o espírito possui uma capacidade de expansão, uma propriedade então associada apenas à matéria, assim como à suas propriedades composicionais. Priestley também ataca a noção de mistério divino, um conceito que, para o autor, abstrai a noção de divindade do homem, o que acarreta na corrpução do cristianismo e na sujeição do homem à religião dogmática. Priestley considera a imposição dogmática como um erro crasso que oprime a imaginação humana, que seria a fonte de toda descoberta e de todo o conhecimento. Essa visão está muito próxima da de Blake, quando em The Marriage ele acusa a religião dogmática de perverter o Gênio Poético, subjugando a imaginação humana.

O poema The Human Abstract, de Songs of Innocence and of Experience (1795), apresenta uma noção interessante a respeito da crítica que Blake formula contra a religião dogmática. A primeira estrofe do poema delega a condição moral de um indivíduo, a vivência de sua virtude moral, a um sistema de emprobrecimento e desiqualdade, uma vez que a noção dogmática da pena só poderia existir em um mundo no qual exista sofrimento: "Pity would be no more,/ If we did not make somebody Poor:/ And Mercy no more could be, If all were as happy as we" (Blake, 1795, p.44). Além disso, o último verso do poema, "[t]here grows one in the Human Brain" (ibidem), sugere que o dogma religioso afeta intrinsecamente a estrutura social, gerando uma condição de humildade forçada, que seria, em suma, fruto de uma abstração reguladora intencionada (um projeto de poder), algo que não teria relação real com os preceitos cristãos - ao menos, não conforme compreendidos por Blake e Priestley.

As ideias filosoficas de matriz lockeana estavam em voga no período de 1790. Apesar da ênfase atribuída por Locke à clareza do pensamento racional, o filósofo também cerca sua noção de divindade por um sentido inescrutável de mistério. Para Locke, o homem percebe através de orgãos de sentido limitados e tudo o que jaz além da capacidade humana de percepção está cercado em obscuridade, e essa seria a instância na qual o filósofo situa Deus. Tal representação se assemelha ao Urizen blakeano, aquele que limita a imaginação humana. A questão principal é que Locke configura o divino como algo que existe além da capacidade de conhecimento humano, excluído dos domínios do pensamento e da percepção, assim como das verdades imanentes do homem.

Por outro lado, Priestley compreende o universo material como uma interação energética entre forças contrárias de atração e repulsão, o que ressoa a afirmativa de Blake em The Marriage: "Attraction and Repulsion, Reason and Energy, Love and Hate, are necessary to Human existence" (Blake, 2011, p.93). Além disso, Priestley rejeita a solidez como uma propriedade inerente à matéria, o que lembra a tentativa falha de Urizen, o demiurgo da obra de Blake, de reduzir o universo a um estado "solid without fluctuation" (Blake, 1794, p.5), em The [First] Book of Urizen. No entanto, o fogo eterno retratado em Urizen também evoca uma imagem priestleyana do universo, na qual a solidez material seria 
de fato sustentada pela energia. Desse modo, a busca de Urizen por "solidity" se mostra politicamente ultrapassada, uma vez que ressoa a manutenção do regime aristocrático, e cientificamente defasada, pois não corresponde ao pensamento contemporâneo da década de 1790 em relação ao tema. Ambas as questões denotam o descompasso de Urizen em relação ao mundo dos sentidos e a vivência do homem, uma vez que, como Blake escreve em There is No Natural Religion (b), "Reason, or the ratio of all we have already known. is not the same that it shall be when we know more" (Blake, 2005, p.53).

Frosch $(1974$, p.19) menciona que Blake acredita que "o corpo humano muda, que possui uma história, tão rica e detalhada quanto a história do pensamento; ele compreende que o corpo natural seria uma invenção do empirismo de Bacon e Locke". Os empiristas, como os supracitados, reasseguram a Deus o Seu aspecto transcendente, compreendendo-o como uma entidade inacessível e incompreensível, o que sugere que o conhecimento humano nunca atingiria um estágio redentório. Deus continua sendo compreendido como uma figura necessária para que se garanta a harmonia universal. Por outro lado, Paley (1985, p.9) comenta que "o mundo natural, de acordo com Priestley, é composto pela energia de Deus", algo que também vai ao encontro da herança boehmista e protestante de Blake. A partir da noção de imanência, proveninente de matrizes gnósticas, Blake sugere que Deus não apenas atua no interior de cada ser, como também na interação empática entre diferentes criaturas. Nesse sentido, a divindade permeia toda a existência, estando presente na essência de cada criatura individual, uma vez que "Each Identity is Eternal", como Blake escreve em The Description of the Last Judgement (Blake, 1988, p.556). Isso, associado às noções de forças agentes priestleyanas e às subversões da doutrina swedenborgiana, sugere uma noção de ação poética e criativa e de redenção calcada na espiritualização da experiência, cuja ação redentória está calcada, principalmente, no amor e no desejo. Como Frosch (1974, p.122) menciona:

Acontece que Blake não está interessado em nenhum Deus, paraíso ou realização que seja inacessível à experiência imediata do corpo. O afastamento da percepção direta, como método confiável de cognição - a trilha que nos foi talhada por Platão, Paulo e Descartes -, produz uma lacuna fatal entre aquilo que é real e aquilo que é percebido, da mesma forma que a subordinação empírica do detalhe sensorial aos padrões mentais; quando o que consideramos como realidade inquestionável é removida do mundo das aparências, o mesmo acontece em relação ao paraíso, que se configura como um estado de nosso completo envolvimento com tal realidade.

Na cópia K de Europe: A Prophecy (Blake, 1821, p.3) existe um prelúdio cantado por uma fada, que apresenta as "Five windows light the cavern'd Man", seguido da enumeraçãos dos cinco sentidos, finalizando com o toque ou tato, a partir do qual o homem poderia "pass out what time he please" (ibidem). Larrissy (1985, p.91) comenta que embora os sentidos sejam limitadores "eles também são libertadores", sendo o sentido do tato aquele que Blake associa 
também ao ato sexual e que "permitiria que a humanidade escapasse de seu aprisionamento" (ibidem, p.92). Além disso, Aubrey (1986) discorre a respeito de uma distinção etimológica - concernente a uma das fontes místicas de Blake: Boehme - entre os termos "carne" (sarx), que se opõe a espírito, e "corpo" (soma), que atua como um produto da união entre entre carne e espírito. Green $(2005$, p.75) comenta que trata-se de "uma relação com o outro que permitiria um acesso à divindade, algo que depende tanto da natureza confinada da sensação corporal [...] quanto da experiência da qual o próprio corpo depende". Ou seja, toda interação humana, seja com o outro ou mesmo com o divino, seria mediada pelo corpo, através dos orgãos dos sentidos.

\section{Considerações finais}

A celebração da sexualidade, como a experiência de união com o divino, foi, ao menos por um tempo, central às crenças da Congregação Moraviana em Fetter Lane, da qual a mãe de Blake fez parte e a qual seu pai também for associado por certo período. Da mesma forma, Swedenborg - que Blake acidamente critica em The Marriage - também praticou, em dado momento, experiências de cunho erótico, calcadas no misticismo judaico. Todavia, "muitas das chocantes cerimônias sexuais dos Moravianos, que inicialmente o atraíram, acabaram por repeli-lo" (Schuchard, 2006, p.50). Também é possível que a leitura de Paradise Lost tenha exercido alguma influência sobre Blake, uma vez que, no canto II, menciona-se que a união sexual entre Adão e Eva é abençoada por Deus. Ou seja, não há apenas consentimento da divindade, mas, além disso, como o arcanjo Rafael menciona no canto VI, tal união oferece acesso ao amor divino. $\mathrm{O}$ contrário disso seria represssão, representada pela "rede infecciosa" de Urizen: a religião dogmática; essa noção condiz com o provérbio de The Marriage: "Prisions are built with stones of Law, Brothels with bricks of Religion" (Blake, 201 1, p.98).

A questão da celebração sexual está ligada à noção de "sensual enjoyment" expressa em The Marriage, que compreende uma espiritualização da experiência material do corpo, um tipo de infusão de energia através da existência, uma força que é ao mesmo tempo celestial e terrestre. Aubrey (1986, p.48) menciona que essa noção de espiritualização do mundo material foi construída a partir da herança boehmista de Blake:

[...] o que Blake de fato encontrou em Boeme, e que está ausente [...] em Swedenborg, foi a visão alquímica da natureza como um vasto e efervescente recipiente para o refinamento e a espiritualização da matéria; uma resposta alquímica, nada menos. Blake certamente reage como um alquimista quando sugere que os escritos de Swedenborg podem ser colocados na mesma categoria da Analítica de Aristóteles.

A resistência de Blake à abstração da divindade, das ideias e das paixões de suas representações corporais torna-se evidente quando observamos sua utilização de figuras verbais e visuais para representar tais instâncias em um caráter 
universal. Utilizando-se de arquétipos próprios, como Urizen, Orc, Enitharmon e Los, Blake intenta substituir as concepções ortodoxas de abstração, mistério e obscuridade da divindade por uma noção de interação entre corpos, que renega também a compreensão da ciência ou da religião baseada na abstração, o que possibilita a libertação da "Lei Moral" - a fundamentação da "rede infecciosa" de Urizen, que está calcada principalmente na noção de pecaminosidade do corpo material. A partir disso, Blake sugere a celebração de energia através da experiência corporal, pois "Energy is Eternal Delight" (Blake, 2011, p.94). Como Green (2005, p.70) destaca, Blake compreendia que "o mundo físico acarreta uma visão do espiritual, em que a instância sensual não é negada nem restrita à busca do prazer filosófico, mas refinada a tal ponto que os prazeres corporais e intelectuais ocorrem simultaneamente".

A convergência de diversas tradições distintas - como materialismo newtoniano, empirismo lockeano, protestantismo antinomiano, moravianismo e alquimia boemista - traçáveis na obra de Blake demonstram suas tentativas de releitura dessas mesmas tradições, o que sugere que o artista intentava criar um ponto de intersecção entre diversas ideias conflitantes, e não que tentava conscientemente fundir ou combinar todas essas discussões em sua obra. É necessário ter em mente que as dicotomias na obra de Blake são menos rígidas do que comumente se poderia supor. Em boa parte de sua obra, Blake, como outros autores, Priestley, por exemplo, tentou situar-se de forma maleável em meio à concepçõe dualistas e binárias, tentando encontrar o acesso ao divino por meio da percepção sensorial, transgredindo as fronteiras da filosofia iluminista, como Locke e Bacon, a fim de produzir uma noção teológico-filosófica de implicações políticas que redimisse o homem de seu estado decaído e da visão do corpo como uma casca passageira e impura.

Agradecimento - O presente trabalho foi realizado com apoio da Coordenação de Aperfeiçoamento de Pessoal de Nível Superior - Brasil (Capes) - Código de Financiamento 001.

\section{Notas}

1 As citações de teoria e crítica foram traduzidas pelo autor diretamente no corpo do texto.

2 Este "corpo ideal" soa demasiadamente platônico. Embora o comentário de Connolly seja pertinente, não creio que Blake tratasse de idealidades. Trata-se justamente do contrário: a percepção da exuberância individual dos corpos enquanto vetores de beleza e paixão. Grifo meu.

\section{Referêcias}

AGLIONBY,W. Painting Illustrated in threedialogues, containingsome Choice Observations upon the Art, Together with the Lives of the most Eminent Painters, 1685, Robert Midgley 
Press. Disponível em: <https://archive.org/details/gri_000033125011129356/page/ n7>. Acesso em: 10 ago. 2018.

AUBREY, B. Watchmen of Eternity: Blake's Debt to Jacob Boebme. London: University Press of America, 1986.

BLAKE, W. America: A Prophecy, cópia A, 1793. Disponível em: <http://www.blakearchive.org/copy/america.a>. Acesso em: 22 out. 2018.

Europe: A Prophey, cópia A, 1794a. Disponível em <http://www.blakearchive.org/work/europe>. Acesso em: 22 nov. 2018.

. The [First] Book of Urizen, Cópia A, 1794b. Disponível em: <http://www. blakearchive.org/copy/urizen.a>. Acesso em: 1 maio 2017.

Songs of Innocence and of Experience. Cópia L, 1795. Disponível em: <http:// www.blakearchive.org/copy/songsie.l>. Acesso em: 21 fev. 2017.

. Elobim Creating Adam, 1795. Disponível em: <https://www.tate.org.uk/ art/artworks/blake-elohim-creating-adam-n05055>. Acesso em: 1 set. 2018.

. Jerusalem The Emanation of The Giant Albion, Cópia E, 1821. Disponível em: <http://www.blakearchive.org/copy/jerusalem.e>. Acesso em: 2 jan. 2016.

. Annotations to the work of Sir Joshua Reynolds. In: ERDMAN, D.; BLOOM, H. The Complete Poetry and Prose of William Blake. New York: Random House, 1988. p.635-62.

. All Religions are One (1788). In: PORTELA, M. Sete Livros Iluminados. Antígona: Lisboa, 2005a. p.32-41.

. There is no Natural Religion (1788). In: PORTELA, M. Sete Livros Iluminados. Antígona: Lisboa, 2005b. p.43-61.

. The Marriage of Heaven and Hell, Cópia B, 1790. In: PHILLIPS, Michael. William Blake: The Marriage of Heaven and Hell. Oxford: Bodleian Library, 2011. p.87-118.

Descriptive Catalogue of Pictures, Poetical And Historical Inventions, 1809. In: Fragmentum, n.42: A poesia e a arte de William Blake: o catálogo descritivo, jul/ set. 2014, UFSM. Disponível em: <https://periodicos.ufsm.br/fragmentum/issue/ view/924/showToc>. Acesso em: 23 mar. 2017.

BURKE, E. Uma investigação filosófica sobre a origem de nossas ideias do sublime e do belo. Trad. Enid Abreu Dobránszky. Campinas: Editora da Universidade de Campinas, 1993.

CONNOLLY, T. J. William Blake and the Body. New York: Palgrave Macmillan, 2002.

FROSCH, T. R. The Awakening of Albion: The Renovation of the Body in the Poetry of William Blake. London: Cornell University Press, 1974.

FRYE, N. Fearful Symmetry - A Study of William Blake. Princeton: Princeton University Press, 1990.

GOMBRICH, E. H. A História da Arte. Trad. Álvaro Cabral. Santos: Nacional (GEN), 2012.

GREEN, M. J. A. Visionary Materialism in the Early Works of William Blake - The Intersection of Enthusiasm and Empiricism. New York: Palgrave Macmillan, 2005.

HARVEY, J. Blake's Art. In: The Cambridge Quarterly, v.7, n.4, p.129-50, jan. 1977. 
HEPPNER, C. Reading Blake's Designs. Cambridge: Cambridge University Press, 1995.

LARRISSY, E. William Blake. Oxford: Blackwell Press, 1985.

MEE, J. Dangerous Enthusiasm: William Blake and the Culture of Radicalism in the 1790s. Oxford: Clarendon, 1992.

MELLOR, A. K. Blake's Human Form Divine. Berkeley, CA: University of California Press, 1974.

MILTON, J. Paradise Lost. Oxford: Blackwell Publishing Ltd, 2007.

PALEY, M. D. Energy and the imagination - A Study of the Development of Blake's Though. Oxford: Oxford University Press, 1985.

PRISTLEY, J. Disquisitions relating to Matter and Spirit (1777). Disponível em: <https://archive.org/details/disquisitionsrel00prie>. Acesso em: 19 set. 2018.

REYNOLDS, J. Discourses on Art, 1723. Ed. Robert R. Wark. San Marino, CA: Huntington Library, 1959.

SCHUCHARD, M. K. Why Mrs Blake Cried: William Blake and the sexual basis of spiritual vision. London: Century, 2006.

VASARI, G. Comentary on Miguel Angelo. In: AGLIONBY, W. Painting illustrated in three diallogues - together with the lives of the most eminent painters. Disponível em: <https://archive.org/details/gri_000033125011129356/page/n7>. Acesso em: 10 ago. 2018.

Lives of the Most Eminent Painters Sculptors and Architects, v.1, 1550. Trad. Gaston du C. de Vere. Londres: Macmillan and CO. LD. \& The Medici Society, LD, 1912-1914. Disponível em: <https://www.gutenberg.org/files/25326/25326-h/25326-h.htm\#Page_121>. Acesso em: 02/01/2017.

WARNER, J. A. Blake and the Language of Art. Montreal: McGill-Queen's University Press, 1984.

RESUMO - William Blake tece, por toda a sua obra, ácidas críticas ao pensamento filosófico de matriz iluminista, em voga entre as classes letradas da Inglaterra do século XVIII, e contra a frequente associação do corpo a um invólucro impuro para alma imortal, leitura comum nas religiões de tradição cristã. Para o artista, a experiência do corpo, apresentado alternadamente como espiritual e material, representa a única via de acesso ao divino. Neste artigo, revisito a tradição crítica sobre as persistentes questões a respeito do corpo e seu papel no acesso humano ao divino presentes na arte iluminada de Blake; tenho o intuito de discutir a convergência politizada de diversas tradições místico-religiosas, filosóficas e artísticas na obra do artista, mantenho-me sensível às contradições geradas por esse processo de aproximação.

PALAVRAS-CHAVE: Corpo, Arte iluminada, Divino, William Blake, Crítica.

ABSTRACT - In all his works, William Blake intensely criticizes both the Enlightenment philosophical thinking in vogue among the cultured classes of 18th-century England, and the understanding of the body as an unclean vessel for the eternal soul, a commom interpretation in Christian traditions. From Blake's point of view, the bodily experiece, 
which is presented in his works dually as material and spiritual, provides the only access to the divine. In this paper, I revisit traditional criticism of Blake's persistent conceptions about the body as the access to the divine. While my essay aims to discuss the politicized convergence of different mystical-religious, philosophical and artistic traditions in Blake's work, I remain aware of the contradictions produced by such approach.

KEYWORDS: Body, Illuminated art, Divine, William Blake, Criticsm.

Andrio J. R. dos Santos é doutor em Letras - Estudos Literários pela Universidade Federal de Santa Maria (UFSM). Atualmente está vinculado ao estágio pós-doutoral do Programa de Pós-Graduação em Letras da UFSM, Bolsa Capes/PNPD, sob a supervisão do Prof. Dr. Anselmo Peres Alós. @- andriosantoscontato@hotmail.com / https://orcid.org/0000-0002-6667-8039.

Recebido em 18.7.2020 e aceito em 23.10.2020.

${ }^{\text {I } U n i v e r s i d a d e ~ F e d e r a l ~ d e ~ S a n t a ~ M a r i a, ~ P r o g r a m a ~ d e ~ P o ́ s-G r a d u a c ̧ a ̃ o ~ e m ~ L e t r a s, ~ S a n t a ~ M a r i a, ~}$ Rio Grande do Sul, Brasil. 